\title{
Change in perception to use of ultrasound in trauma and ICU: A questionnaire based survey
}

Karjome Lama , Amit Thapa , Bidur KC, Bikram Shakya

Department of Neurological Surgery, Kathmandu Medical College

Teaching Hospital, Sinamangal, Kathmandu

Correspondence : Dr Amit Thapa, Associate Professor,Department of Neurological Surgery, Kathmandu Medical College Teaching Hospital, Sinamangal, Kathmandu

Email: dramitthapa@yahoo.com

\begin{abstract}
Introduction and Objective: We since 2012 have been routinely conducting KUTLS (KMCTH ultrasound trauma life support) courses. Unlike detailed examination of an organ with an ultrasound as performed by radiologist, we profess sonoscopic based problem solving approach for the clinician as he uses his stethoscope. The initial skepticism to use of sonoscope in a systematic methodical way has been seen to be fading. We conducted a survey to see the change in attitude of the clinicians with the
\end{abstract} training program.

Materials and Methods: We study the questionnaire based feedback forms of the participants in the last 5 course of KUTLS workshop and analysed the change in scores of the post test.

Results: 152 delegates actively participated in 5 sessions of KUTLS workshops during the last 3 years. The most common reasons to attend the workshop was to develop the skill with sonoscope with almost 95\% participant not having any past experience of sonoscopy. Almost $98 \%$ scored more than $75 \%$ in the post test suggesting fast learning curve and interest among the learners. Almost $100 \%$ were convinced with the applicability of the USG and had wished to change their practice.

Conclusion: A structured use of sonoscope would be helpful in clinical practice particularly in solving difficult questions in trauma and ICU. Workshops and seminars help change attitude and practice of the participants even with no prior formal training in ultrasound.

Key words: ultrasound, attitude, practice, ICU, trauma 